\title{
Toric intraocular lenses for correction of astigmatism in keratoconus and after corneal surgery
}

This article was published in the following Dove Press journal:

Clinical Ophthalmology

21 June 2016

Number of times this article has been viewed

Ilse EMA Mol ${ }^{1,2}$

Bart TH Van Dooren ${ }^{1,2}$

'Department of Ophthalmology, Amphia Hospital, Breda, ${ }^{2}$ Department of Ophthalmology, Erasmus Medical Center, Rotterdam, the Netherlands
Correspondence: Ilse EMA Mol Department of Ophthalmology, Erasmus Medical Center, Gravendijkwal 230, 3015 CE Rotterdam, the Netherlands $\mathrm{Tel}+31 \quad 107040135$

Fax +3। 107033692

Email i.mol@erasmusmc.nl
Purpose: To describe the results of cataract extraction with toric intraocular lens (IOL) implantation in patients with preexisting astigmatism from three corneal conditions (keratoconus, postkeratoplasty, and postpterygium surgery).

Methods: Cataract patients with topographically stable, fairly regular (although sometimes very high) corneal astigmatism underwent phacoemulsification with implantation of a toric IOL (Zeiss AT TORBI 709, Alcon Acrysof IQ toric SN6AT, AMO Tecnis ZCT). Postoperative astigmatism and refractive outcomes, as well as visual acuities, vector reduction, and complications were recorded for all eyes.

Results: This study evaluated 17 eyes of 16 patients with a mean age of 60 years at the time of surgery. Mean follow-up in this study was 12 months. The corrected distance Snellen visual acuity (with spectacles or contact lenses) 12 months postoperatively was $20 / 32$ or better in $82 \%$ of eyes. The mean corneal astigmatism was 6.7 diopters (D) preoperatively, and $1.5 \mathrm{D}$ of refractive cylinder at 1 -year follow-up. No vision-compromising intra- or postoperative complications occurred and decentration or off-axis alignment of toric IOLs were not observed.

Conclusion: Phacoemulsification with toric IOL implantation was a safe and effective procedure in the three mentioned corneal conditions. Patient selection, counseling, and IOL placement with optimal astigmatism correction are crucial.

Keywords: toric intraocular lens, phacoemulsification, corneal astigmatism, keratoconus, postkeratoplasty, postpterygium surgery

\section{Introduction}

Toric intraocular lenses (IOLs) can be used at the time of cataract surgery to decrease postoperative astigmatism. Several studies have been published on toric lenses demonstrating significant reduction in spherical and astigmatic refractive errors with good efficacy, safety, and predictability in cataract patients. ${ }^{1,2}$ Additionally, in selected patients with corneal conditions, toric IOL implantation showed promising results. $^{3-6}$

However, the safety and effectiveness of toric IOLs have not been fully substantiated in patients with preexisting ocular conditions. Concerns still exist regarding potentially induced higher order aberrations due to complex coupling of the IOLs toricity with the corneal irregularity. Furthermore, irregular astigmatism seems to be a relative contraindication for toric IOL implantation. ${ }^{7}$

We performed this study to evaluate the visual and refractive outcomes of toric IOL implantation in cataract patients with topographically stable, although sometimes 
very high, corneal astigmatism resulting from three corneal conditions (keratoconus, postkeratoplasty, and postpterygium surgery). Correcting the refractive error in these conditions is an off-label use of toric IOLs.

\section{Materials and methods}

In this retrospective study, patients were included who underwent routine cataract surgery and toric IOL implantation between April 2011 and December 2013. All surgeries were performed by one surgeon (BVD) at the Amphia Hospital Breda, the Netherlands. Patients gave informed consent in this retrospective study for the implantation of a toric IOL. According to national regulations, obtaining institutional review board approval for conducting a retrospective study such as the present study, is not mandatory. Patients were extensively informed and consented about the procedure (orally, with written information as needed by the patient), before operation. Surgery was performed in accordance with the usual, high, clinical standards. Follow-up was performed at regular post-operative intervals and all relevant parameters were recorded.

Preoperatively, all patients underwent a complete ophthalmic evaluation including subjective refraction, Snellen best-corrected distance visual acuity (BCVA), applanation tonometry, slit-lamp examination, funduscopy, and corneal topography (type 70900, Pentacam HR, Oculus Optikgeräte GmbH, Wetzlar, Germany). Optical biometry was measured with the IOLMaster (Carl Zeiss Meditec AG, Jena, Germany) and if this was not possible due to the density of the cataract, it was measured by A scan ultrasonography (Nidek US-500, Gamagori, Japan). Endothelial cell counts were evaluated by confocal microscopy (Confoscan 4, Nidek, Padova, Italy) for all patients.

\section{Inclusion and exclusion criteria}

Inclusion criteria for toric IOL implantation were visually significant cataract, fairly regular corneal astigmatism of $1.25 \mathrm{D}$ or more, a bow tie-like pattern on corneal topography and corneal-based astigmatism correctable with spectacles. Refraction had to be stable during multiple tomography examinations (total corneal refractive power map). Stable and nonprogressive astigmatism over a 6-month period was defined as no $>1.00 \mathrm{D}$ variation in the maximum topographic keratometry $(\mathrm{K})$ value. After corneal surgery, this definition was used on the precondition of complete suture removal.

Exclusion criteria included endothelial cell count $<1,500 / \mathrm{mm}^{2}$, irregular astigmatism unable to be corrected with spectacles and ocular comorbidities that could have an impact on capsular bag stability, affect visual acuity, or the quality of vision. The severity of keratoconus was classified as mild, moderate, or severe according to the average $\mathrm{K}$ readings and based on the classification of Krumeich et al. ${ }^{8}$ Patients with severe keratoconus (average K readings > 55 D) were excluded from this study.

\section{Surgical technique}

Surgery was performed using sub-Tenon's anesthesia, except for one patient who preferred general anesthesia. Before the sub-Tenon's block, the 3, 6, and 9 o'clock corneal markings were made with Nuijts-Lane Toric Reference Marker (AE-2791TBL, ASICO, Westmont, IL, USA) under topical anesthesia. Patients were instructed to sit upright and look forward to avoid supine cyclotorsion. Intraoperatively, the location of the corneal incision and axis of IOL placement was marked using Mendez degree gauge (AE-2765N, ASICO) and a Nuijts-Solomon Toric Axis Marker (AE-2740N, ASICO). A superotemporal nearclear corneal incision was created in the keratoconus and postpterygium patients; corneoscleral incisions were made in postkeratoplasty patients. This was followed by injection of an ophthalmic viscosurgical device, capsulorhexis, phacoemulsification, bimanual irrigation/aspiration of cortical material, filling of the capsular bag with viscoelastic material, toric IOL implantation and thorough irrigation and aspiration, ensuring complete removal of residual viscoelastic behind the IOL as the standard procedure. During surgery, a dispersive ophthalmic viscosurgical device (hydroxypropyl methylcellulose 2\%, Viscomet, Sun Pharmaceuticals Industries Ltd, Mumbai, India) was used to protect the endothelium. The toric IOL was aligned with the corneal marks and a final check was made when the incisions were hydrated. Postoperatively, a standard regimen of topical nonsteroidal and steroid anti-inflammatory drops was used.

\section{Toric IOLs and power calculation}

Toric IOLs were used from three different manufacturers: AT TORBI 709 (Carl Zeiss Meditec AG), Tecnis Toric ZCT IOL (Abbott Medical Optics, Inc, Santa Ana, CA, USA), and Acrysof SN6AT toric IOL (Alcon Laboratories, Inc., Fort Worth, TX, USA). All the three types are single-piece toric IOLs. Because of its cylinder power range $(+12.00 \mathrm{D}$ to $+1.00 \mathrm{D}$ ), Zeiss AT TORBI 709 was used for cataract patients with high amounts of corneal astigmatism. In the beginning, Acrysof SN6AT was placed in cataract patients with moderate amounts of astigmatism because it was the most readily available toric IOL. In the later years, AMO Tecnis ZCT toric IOL became our standard IOL for cataract patients with moderate astigmatism. 


\section{Patient assessment and postoperative follow-up}

Preoperative biometry and topographic keratometry, the expected amount of surgically induced astigmatism, and the site of incision were used to determine the appropriate toric IOL model, alignment axis, and spherical equivalent (SE) power. The Haigis formula was used as the main method for spherical IOL power calculation and compared with the SRK/T, Hoffer-Q, and Holladay 1 formulas. ${ }^{9-13}$ Toric IOL power calculation and orientation placement were performed using the software provided by the manufacturer of the IOLs. ${ }^{14-16}$

\section{Analysis}

Patients were seen 1 day, 1 week, and 1,3,6, and 12 months after cataract surgery whenever possible. All eyes were examined at each postoperative visit, including visual acuity, refraction, applanation tonometry, and slit-lamp examination. Postoperatively, the orientation axis of the toric IOL was determined by using the biomicroscope and full mydriasis of the pupil.

Visual outcomes are presented in the form of BCVA with spectacles or contact lenses. Refractive data are provided in the form of sphere, positive cylinder, and cylinder axis. For analysis purposes, visual acuities were converted from Snellen acuity to $\log$ MAR. ${ }^{17}$

Based on the results, we calculated the safety index (ratio of postoperative BCVA over preoperative BCVA). The efficacy index (ratio of postoperative uncorrected visual acuity over preoperative BCVA) could not be examined due to lack of standardized postoperative uncorrected visual acuity data in this retrospective study.

A full description of refractive error was done with the three-dimensional vector that takes into account magnitude and axis of astigmatism as well as the spherical component. Therefore, spherocylindrical refraction results (S [sphere], $\mathrm{C}$ [cylinder], $\alpha$ [axis]) were converted to power vector coordinates $\mathrm{M}, \mathrm{J}_{0}$, and $\mathrm{J}_{45}$ by the following formulas:

$$
\begin{gathered}
\mathrm{M}=\mathrm{S}+\mathrm{C} / 2 \\
\mathrm{~J}_{0}=(-\mathrm{C} / 2) * \cos (2 \alpha) \\
\mathrm{J}_{45}=(-\mathrm{C} / 2) * \sin (2 \alpha),
\end{gathered}
$$

where $\mathrm{M}$ is equal to the $\mathrm{SE}$ of the given refractive error; $\mathrm{J}_{0}$ is the Jackson cross-cylinder, axes at $90^{\circ}$ and $180^{\circ} ; \mathrm{J}_{45}$ is the Jackson cross-cylinder, axes at $45^{\circ}$ and $135^{\circ} .18-20$

\section{Results}

We retrospectively studied 17 eyes of 16 patients, four (25\%) females and $12(75 \%)$ males. Mean patient age at
Table I Baseline parameters

\begin{tabular}{llll}
\hline Patients (n) & 6 & 7 & 3 \\
Eyes (n) & 6 & 8 & 3 \\
Age (years) & $59 \pm 9$ & $54 \pm 8$ & $74 \pm 6$ \\
Refractive sphere (D) & $-7.4 \pm 3.0$ & $-6.0 \pm 4.7$ & $-0.5 \pm 0.7$ \\
Refractive cylinder (D) & $4.0 \pm 1.8$ & $5.5 \pm 3.4$ & $4.7 \pm 1.6$ \\
Refractive SE (D) & $-5.4 \pm 2.4$ & $-3.3 \pm 3.9$ & $1.8 \pm 0.3$ \\
Corneal astigmatism (D)* & $6.1 \pm 5.9$ & $7.3 \pm 4.3$ & $3.9 \pm 0.4$ \\
IOL sphere (D) & $6.7 \pm 8.3$ & $10.2 \pm 10.3$ & $21.3 \pm 1.0$ \\
IOL cylinder (D) & $5.8 \pm 3.0$ & $7.3 \pm 4.3$ & $4.4 \pm 0.6$ \\
IOL SE (D) & $9.6 \pm 6.9$ & $13.8 \pm 9.1$ & $23.5 \pm 1.2$ \\
AT TORBI 709, Carl Zeiss (n) & 1 & 4 & 0 \\
Tecnis Toric ZCT IOL Abbott (n) & 2 & 2 & 2 \\
Acrysof SN6AT Alcon (n) & 3 & 2 & 1
\end{tabular}

Notes: Data are expressed as mean \pm SD. *Pentacam-derived (SimK).

Abbreviations: IOL, intraocular lens; SD, standard deviation; SE, spherical equivalent.

the time of surgery was $60 \pm 11$ years. Table 1 shows the demographic data prior to surgery, types, and parameters of implanted lenses. The AMO ZCT toric IOL was implanted in six patients (six eyes), Zeiss AT TORBI 709 in four patients (five eyes), and six patients (six eyes) received the Alcon Acrysof IQ toric SN6AT toric IOL.

\section{Complications}

No vision-compromising intraoperative complications occurred. One patient suffered from postoperative macula-on retinal detachment, which could be surgically repaired without loss of vision. Decentration or off-axis alignment of the toric IOL was not observed, and no graft had rejection episodes.

\section{Visual acuity}

Visual outcomes are presented in BCVA (or contact lens visual acuity in one patient). Figure 1 shows the BCVA

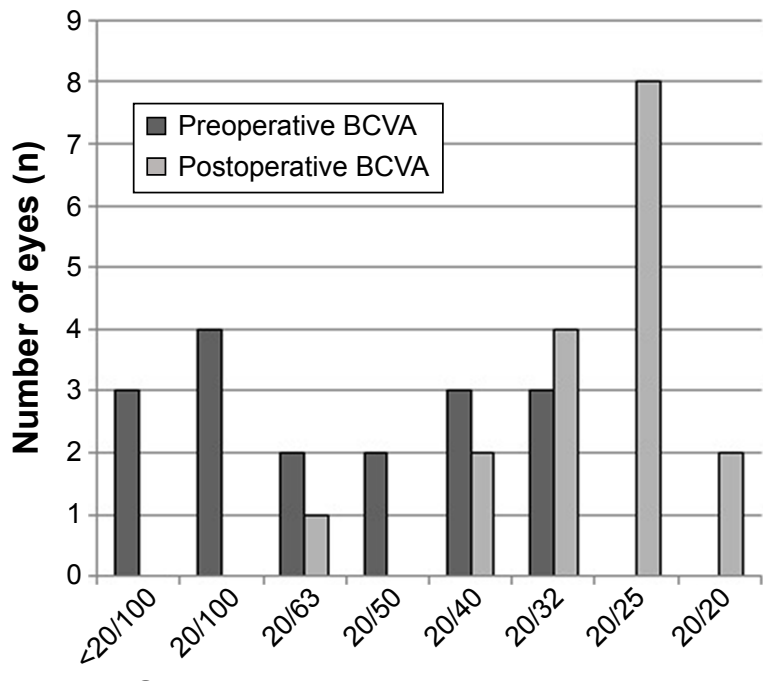

Snellen visual acuity $(20 / \times$ or better)

Figure I Preoperative versus I2-month postoperative BCVA.

Abbreviation: BCVA, best-corrected visual acuity. 
before toric IOL implantation and after a mean follow-up period of 12 months postoperatively. The mean BCVA was $0.59 \pm 0.44 \log$ MAR preoperative and $0.13 \pm 0.13 \log$ MAR 1 year postoperative. The corrected distance Snellen visual acuity 12 months postoperatively was 20/32 (0.6) or better in 14 eyes $(82 \%)$ and $20 / 25(0.8)$ or better in ten eyes $(59 \%)$.

\section{Refraction}

The mean refractive SE decreased from $-3.10 \pm 3.95 \mathrm{D}$ preoperatively to $0.22 \pm 1.53 \mathrm{D}$ postoperatively.

\section{Safety}

The safety results for toric IOL implantation are presented in Figure 2. There was loss of one line in one patient, likely due to a macular pucker with metamorphopsia. All other eyes gained two lines or more. The mean safety index was $4.88 \pm 8.02$.

\section{Predictability}

Figure 3 shows the distribution of manifest preoperative corneal astigmatism and the refractive cylinder at a mean of 12 months postsurgery. The mean refractive cylinder decreased from $6.3 \pm 4.7 \mathrm{D}$ preoperatively to $1.5 \pm 1.5 \mathrm{D}$ at 1 year after toric IOL implantation.

\section{Vector analysis}

Figure 4 shows the scatter plot of the astigmatic vectors $\left(\mathrm{J}_{0}, \mathrm{~J}_{45}\right)$ before and after toric IOL implantation. The more central location of postoperative data around 0 represents the reduction of preoperative astigmatism by the implantation

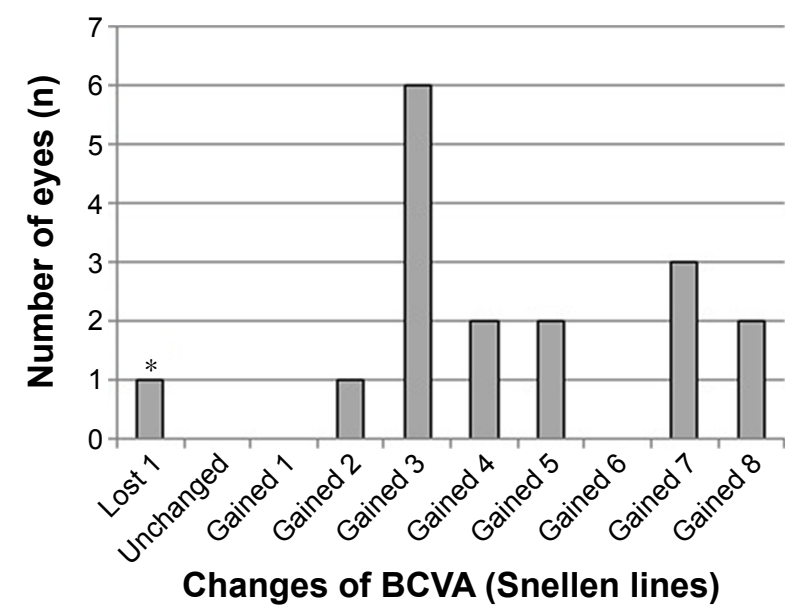

Figure 2 Changes in BCVA (Snellen chart) after 12 months of toric intraocular lens implantation.

Note: *Comorbidity: macular pucker with metamorphopsia (postoperative BCVA 0.6).

Abbreviation: BCVA, best-corrected visual acuity.

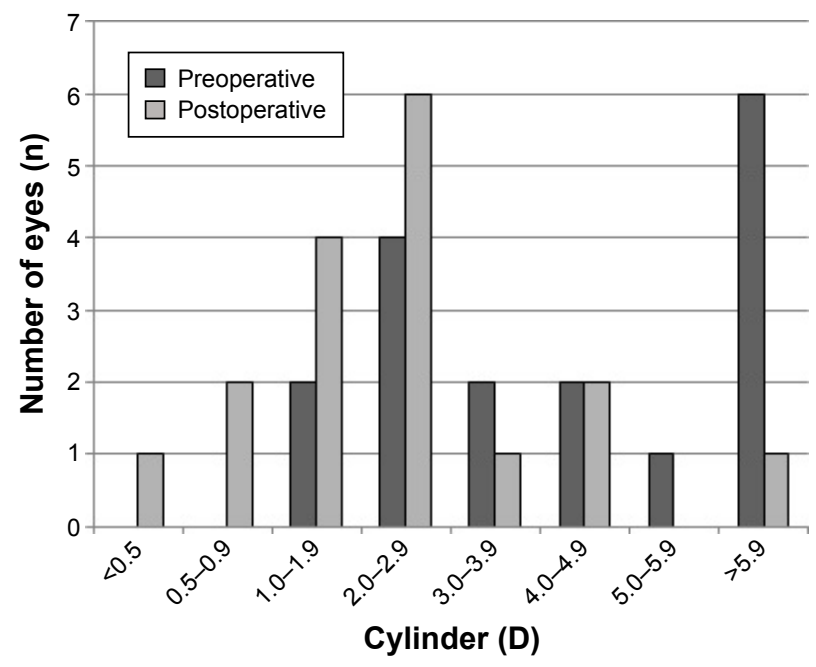

Figure 3 Preoperative corneal astigmatism versus 12-month postoperative refractive cylinder distribution in diopters (D).

of the toric implantable IOL. The value $(0,0)$ represents an eye free of astigmatism. Mean M dropped from 3.1 \pm 3.9 to $0.1 \pm 1.5$. $\mathrm{J}_{0}$ dropped from $0.9 \pm 0.9$ to $-0.1 \pm 0.3$. $\mathrm{J}_{45}$ changed from $0.7 \pm 0.6$ to $-0.1 \pm 0.5$.

\section{Patient satisfaction}

Overall, patient satisfaction was fairly good for most patients. Although phacoemulsification and toric IOLs implantation did not provide total refractive correction, most patients were pleased with the improvement they experienced. In our group of patients, slight residual refraction error was well tolerated and wearing spectacles or contact lenses usually was not a problem. Two patients were less satisfied because of comorbidity from a macular pucker $(\mathrm{n}=1)$ and the additional need for a scleral contact lens because of the residual anisometropia $(\mathrm{n}=1)$. By using the scleral contact lens, the patient achieved a postoperative BCVA of 20/30 (0.7).

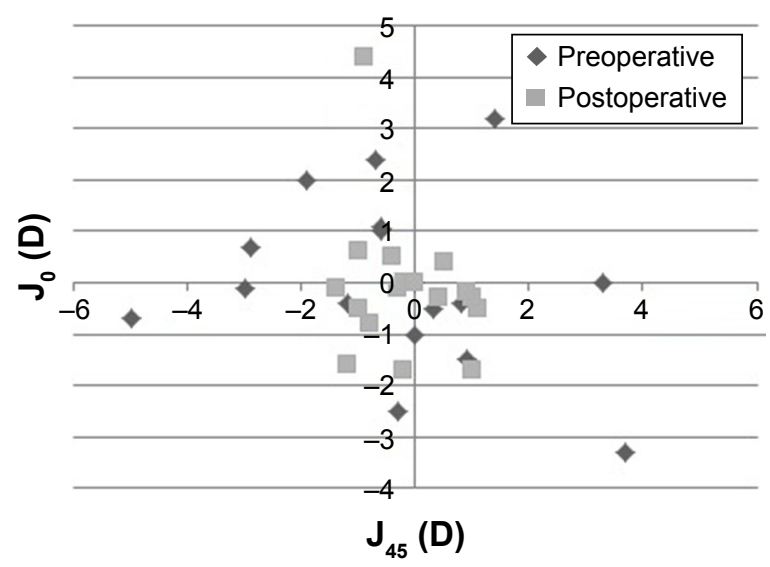

Figure 4 Scatter plot of the astigmatic vectors $\left(J_{0}\right.$ and $\left.J_{45}\right)$ before and after toric intraocular lens implantation. 
Initially, one patient was less satisfied because of the conversion from myopia to slight hypermetropia (SE +1.0 D, target was emmetropia). This patient went back to isometropia after cataract surgery of the other eye and was happy wearing multifocal spectacles.

\section{Discussion}

In our series, phacoemulsification with toric IOL implantation for visually significant cataract was a safe and effective procedure in the three corneal conditions (keratoconus, postkeratoplasty, and postpterygium surgery). Our results are in agreement with previously published case reports and series on toric IOL implantation for correcting postkeratoplasty astigmatism and keratoconus in cataract patients. ${ }^{3,6,21-27}$

To our knowledge, no previous studies reported the outcomes of toric IOL implantation in patients having phacoemulsification after previous pterygium surgery. Furthermore, most of the available literature reports results from only the Acrysof toric IOL since this is one of the most commonly used toric IOL in cataract surgery. We, however, were able to show the safety and effectiveness of toric IOLs from three different manufacturers.

In our series, one male patient suffered from macula-on retinal detachment about 5 weeks postoperatively. Fortunately, the detachment was recognized early and repaired before loss of vision occurred. This complication was one typically associated with cataract surgery and high myopia. ${ }^{28}$ Our myopic keratoconus patient had an axial length of 27.99 $\mathrm{mm}$ and therefore was prone to retinal detachment.

In this study, toric IOL implantation was only considered in patients with stable corneal pathology and fairly regular astigmatism. Extensive preoperative corneal topography, including total corneal power analysis and several consecutive examinations over a longer time period, is crucial. If endothelial graft failure should occur, the existing refractive situation after insertion of a toric IOL may be maintained by proceeding with endothelial keratoplasty.

For patients who wish to continue to wear a contact lens after surgery, there is uncertainty as to the optimum target for postoperative refraction for optimal postoperative contact lens fit. If a patient wants to return to a rigid (bi)toric or scleral contact lens after toric IOL implantation, the astigmatism of the IOL will become manifest. A bitoric rigid gas permeable design may then be necessary. Alternatively, the toric IOL may be exchanged for a spherical IOL design. ${ }^{29}$ Therefore, it should be emphasized that toric IOL implantation is a suitable option only in patients with astigmatism who can be satisfactorily corrected with spectacles and have realistic expectations.
In most cases, the treatment provided was not expected to fully correct the patient's eyesight to emmetropia. It is advisable to remain on the conservative (myopic) side with choice of target SE. Slight residual astigmatism may also be beneficial because of increased depth of focus. Our patients were counseled regarding the limitations of the toric IOL in fully correcting the astigmatism. The operating surgeon should be aware of the tendency toward hyperopic outcomes in any cataract surgery in steep keratoconic corneas. Biometry in eyes with severe keratoconus will typically overestimate the corneal power and underestimate the IOL power, with a tendency to postoperative hyperopic biometry prediction error. ${ }^{8,30}$ Therefore, we only included patients with mild and moderate amounts of keratoconus.

It is not surprising that, in the present study, there was a large reduction in the mean refractive SE. The decrease in the magnitude of astigmatism reflects that the toric IOLs effectively addressed that component. The decrease from $-3.10 \pm 3.95 \mathrm{D}$ preoperatively to a postoperative SE of $0.22 \pm 1.53 \mathrm{D}$ reflects successful reduction in astigmatism with some cases of mild overcorrection. This stresses the importance of a myopic target with the postoperative hyperopic prediction error as described earlier.

The technique we used to mark the axis of IOL alignment preoperatively and confirm alignment by using the biomicroscope postoperatively is not flawless. However, we did not find significant rotational misalignment at last follow-up, which is in agreement with previously published reports showing good rotational stability for the three types of toric IOLs. ${ }^{2,31-33}$

Mean safety index was $4.88 \pm 8.02$. When analyzing this high value, especially the amount of standard deviation, it is important to take into account the fact that the improvement in BCVA derives not only from the correction of refractive astigmatism, but also from the removal of cataract. The BCVA of one patient increased from distinguishing hand movements at a distance of 10 feet to a postoperative BCVA of 20/63. Due to this specific case, the standard deviation increased.

Our vector analysis was based on the three-dimensional vector that takes into account magnitude and axis of astigmatism, as well as the spherical component. Because astigmatism analysis is multidimensional, it is not possible to capture the nuances in a single graphical display. There are other, possibly superior, methods of reporting on the manifest refractive astigmatism before and after a procedure. Given the complexity of analyzing astigmatism, there are inevitable differences between these approaches; so far, absolute agreement on a standard has not been reached. ${ }^{34}$ 
We acknowledge that there are limitations to this retrospective study. There is a degree of heterogeneity in our cohort of patients and the cohort is small, which makes basic statistical comparison inappropriate. However, we believe that we were able to show meaningful long-term visual and refractive results with overall good patient satisfaction. As always, careful patient selection and thorough and complete patient information are paramount.

\section{Acknowledgment}

Presented at the World Cornea Congress VII (WCCVII), San Diego, CA, April 2015.

\section{Disclosure}

The authors did not receive any financial support from any public or private sources. The authors have no financial or proprietary interest in a product, method, or material described herein. The authors report no conflicts of interest in this work.

\section{References}

1. Hoffmann PC, Auel S, Hütz WW. Results of higher power toric intraocular lens implantation. J Cataract Refract Surg. 2011;37(8):1411-1418.

2. Miyake T, Kamiya K, Amano R, Iida Y, Tsunehiro S, Shimizu K. Longterm clinical outcomes of toric intraocular lens implantation in cataract cases with preexisting astigmatism. J Cataract Refract Surg. 2014;40(10): 1654-1660.

3. Visser N, Gast ST, Bauer NJ, Nuijts RM. Cataract surgery with toric intraocular lens implantation in keratoconus: a case report. Cornea. 2011;30(6):720-723.

4. Luck J. Customized ultra-high-power toric intraocular lens implantation for pellucid marginal degeneration and cataract. $J$ Cataract Refract Surg. 2010;36(7):1235-1238.

5. Kersey JP, O’Donnell A, Illingworth CD. Cataract surgery with toric intraocular lenses can optimize uncorrected postoperative visual acuity in patients with marked corneal astigmatism. Cornea. 2007;26(2): 133-135.

6. Stewart CM, McAlister JC. Comparison of grafted and non-grafted patients with corneal astigmatism undergoing cataract extraction with a toric intraocular lens implant. Clin Experiment Ophthalmol. 2010; 38(8):747-757.

7. Kugler LJ, Sztipanovits D, Wang M. Contraindications to implantation of toric IOLs. Refrac Eyecare. 2011;15(3):26-28.

8. Krumeich JH, Daniel J, Knülle A. Live-epikeratophakia for keratoconus. J Cataract Refract Surg. 1998;24(4):456-463.

9. Haigis W, Lege B, Miller N, Schneider B. Comparison of immersion ultrasound biometry and partial coherence interferometry for intraocular lens calculation according to Haigis. Graefes Arch Clin Exp Ophthalmol. 2000;238(9):765-773.

10. Petermeier K, Gekeler F, Messias A, Spitzer MS, Haigis W, Szurman P. Intraocular lens power calculation and optimized constants for highly myopic eyes. J Cataract Refract Surg. 2009;35(9):1575-1581.

11. Retzlaff JA, Sanders DR, Kraff MC. Development of SRK/T intraocular lens implant power calculation formula. J Cataract Refract Surg. 1990;16(3):333-340.
12. Hoffer KJ. The Hoffer Q formula: a comparison of theoretic and regression formulas. J Cataract Refract Surg. 1993;19(6):700-712.

13. Holladay JT, Prager TC, Chandler TY, Musgrove KH, Lewis JW, Ruiz RS. A three-part system for refining intraocular lens power calculations. J Cataract Refract Surg. 1988;14(1):17-24.

14. AcrySof ${ }^{\mathbb{\circledR}}$ Toric IOL Web Based Calculators. Available from: http:// www.acrysoftoriccalculator.com/

15. Abbott Laboratories Inc., AMO IOL Calculator Platform. Available from: http://amoeasy.com/calc

16. Carl Zeiss Meditec IOLMaster Online, Toric IOL Calculator. Available from: http://www.zeiss.com/iolmaster-online

17. Holladay JT. Proper method for calculating average visual acuity. J Refract Surg. 1997;13(4):388-391.

18. Thibos LN, Horner D. Power vector analysis of the optical outcome of refractive surgery. J Cataract Refract Surg. 2001;27(1):80-85.

19. Mertens EL. Toric phakic implantable collamer lens for correction of astigmatism: 1-year outcomes. Clin Ophthalmol. 2011;5:369-375.

20. Thibos LN, Wheeler W, Horner D. Power vectors: an application of Fourier analysis to the description and statistical analysis of refractive error. Optom Vis Sci. 1997;74(6):367-375.

21. Navas A, Suárez R. One-year follow-up of toric intraocular lens implantation in forme fruste keratoconus. J Cataract Refract Surg. 2009;35(11): 2024-2027.

22. De Sanctis U, Eandi C, Grignolo F. Phacoemulsification and customized toric intraocular lens implantation in eyes with cataract and high astigmatism after penetrating keratoplasty. J Cataract Refract Surg. 2011;37(4): 781-785.

23. Buchwald HJ, Lang GK. Cataract surgery with implantation of toric silicone lenses for severe astigmatism after keratoplasty. Klin Monbl Augenheilkd. 2004;221(6):489-494.

24. Frohn A, Dick HB, Thiel HJ. Implantation of a toric poly(methyl methacrylate) intraocular lens to correct high astigmatism. J Cataract Refract Surg. 1999;25(12):1675-1678.

25. Lockington D, Wang EF, Patel DV, Moore SP, McGhee CN. Effectiveness of cataract phacoemulsification with toric intraocular lenses in addressing astigmatism after keratoplasty. $J$ Cataract Refract Surg. 2014;40(12):2044-2049.

26. Hashemi H, Heidarian S, Seyedian MA, Yekta A, Khabazkhoob M. Evaluation of the results of using toric IOL in the cataract surgery of keratoconus patients. Eye Contact Lens. 2015;41(6):354-358.

27. Wade M, Steinert RF, Garg S, Farid M, Gaster R. Results of toric intraocular lenses for post-penetrating keratoplasty astigmatism. Ophthalmology. 2014;121(3):771-777.

28. Russell M, Gaskin B, Russell D, Polkinghorne PJ. Pseudophakic retinal detachment after phacoemulsification cataract surgery: ten-year retrospective review. J Cataract Refract Surg. 2006;32(3):442-445.

29. Watson MP, Anand S, Bhogal M, et al. Cataract surgery outcome in eyes with keratoconus. Br J Ophthalmol. 2014;98(3):361-364.

30. Alpins N, Onj JK, Stamatelatos G. Refractive surprise after toric intraocular lens implantation: graph analysis. J Cataract Refract Surg. 2014;40(2):283-294.

31. Bascaran L, Mendicute J, Macias-Murelaga B, Arbelaitz N, MartinezSoroa I. Efficacy and stability of AT TORBI 709 M toric IOL. J Refract Surg. 2013;29(3):194-199.

32. Ferreira TB, Almeida A. Comparison of the visual outcomes and OPDscan results of AMO Tecnis toric and Alcon Acrysof IQ toric intraocular lenses. J Refract Surg. 2012;28(8):551-555.

33. Hirnschall N, Maedel S, Weber M, Findl O. Rotational stability of a single-piece toric acrylic intraocular lens: a pilot study. Am JOphthalmol. 2014;157(2):405-411.

34. Reinstein DZ, Archer TJ, Randleman JB. JRS standard for reporting astigmatism outcomes of refractive surgery. J Refract Surg. 2014;30(10): 654-659. 
Clinical Ophthalmology

\section{Publish your work in this journal}

Clinical Ophthalmology is an international, peer-reviewed journal covering all subspecialties within ophthalmology. Key topics include: Optometry; Visual science; Pharmacology and drug therapy in eye diseases; Basic Sciences; Primary and Secondary eye care; Patien Safety and Quality of Care Improvements. This journal is indexed on

Submit your manuscript here: http://www.dovepress.com/clinical-ophthalmology-journal

PubMed Central and CAS, and is the official journal of The Society of Clinical Ophthalmology (SCO). The manuscript management system is completely online and includes a very quick and fair peer-review system, which is all easy to use. Visit http://www.dovepress.com/ testimonials.php to read real quotes from published authors. 